\title{
Inhibition of Helicobacter pylori Motility by (+)-Syringaresinol from Unripe Japanese Apricot
}

\author{
Mitsuo Miyazawa, ${ }^{*, a}$ Hirotoshi Utsunomiya, ${ }^{b}$ Ken-ichi Inada, ${ }^{c}$ Tomoki Yamada, ${ }^{a}$ \\ Yoshiharu OKUNO, ${ }^{a}$ Harunari TANAKA, ${ }^{d}$ and Masae TATEMATSU ${ }^{d}$ \\ ${ }^{a}$ Department of Applied Chemistry, Faculty of Science and Engineering, Kinki University; Kowakae, Higashiosaka, Osaka \\ 577-8502, Japan: ${ }^{b}$ Department of Pathology, Wakayama Medical University; Kimiidera, Wakayama, Wakayama \\ 641-0012, Japan: ${ }^{c}$ 1st Department of Pathology, Fujita Health University School of Medicine; Toyoake, Aichi 470-1192, \\ Japan: and ${ }^{d}$ Division of Oncological Pathology, Aichi Cancer Center Reseach Institute; 1-1 Kanokoden, Chikusa-ku, \\ Nagoya 464-8681, Japan. Received May 26, 2005; accepted October 12, 2005; published online October 17, 2005
}

\begin{abstract}
A methanol extract from unripe Japanese apricot showed inhibitory activity of Helicobacter pylori motility. Inhibitory compound 1 was isolated and identified as (+)-syringaresinol (1) by spectoroscopic means. (+)-Syringaresinol (1) inhibited $>90 \%$ of the $H$. pylori motility at a concentration of $500 \mu \mathrm{g} / \mathrm{ml}$ and the $\mathrm{IC}_{50}$ value was $50 \mu \mathrm{g} / \mathrm{ml}$.
\end{abstract}

Key words Helicobacter pylori; (+)-syringaresinol; Japanese apricot

Helicobacter pylori was isolated from the gastric antrum of chronic gastritis patients. H. pylori is closely associated with gastritis and peptic ulcers and is even a bacterial risk factor for gastric cancer. ${ }^{1-4)}$ Therefore, eradication of the bacteria and inhibition of the urease are important for the treatment of patients with gastroduodenal diseases.

The standard treatment for $H$. pylori related disease is a combination of antimicrobial agents and anti-acid agent. ${ }^{5}$ However, the drug resistant $H$. pylori against most effective antimicrobials, metronidazole and clarithromycin, is commonplace in many societies and is of particular concern as the major reason for treatment failure. ${ }^{6-8)} \mathrm{H}$. pylori is a spiral-shapes, strongly motile bacterium, and the motility is generally held to be a requirement for colonization of the stomach. $\left.{ }^{9}, 10\right)$ Thus, one possible approach for prevention of $H$. pylori infection would be to inhibit the $H$. pylori motility.

The Japanese apricot (Prunus mume SiBE. et. Zucc.; Ume), a deciduous tree of the family Rosaceae, originated in the central and southern regions of China, and has now 400 500 varieties worldwide. The fruits of Japanese apricot are taken in foods as umeboshi, Bainiku-ekisu, pickled Japanese apricot, ume liquor and ume-based soft drinks. The fruit has been known to have various biological activities, and the fruit has been prescribed medicine for disorder of the stomach and intestines, quick recovery from fatigue, cough and diarrhea in Chinese traditional prescriptions. ${ }^{11,12)}$ However, very few reports are available that proofs of components from Japanese apricot are effective against diseases.

During the screening program to discover such compounds from natural products, Japanse apricot was found to show inhibitory activity against $H$. pylori motility. In this paper, we report the isolation and identification of inhibitor of $H$. pylori motility from unripe Japanese apricot.

\section{MATERIALS AND METHODS}

General Melting point was measured on a Micro Melting Point Meter MP-500D. Optical rotation was measured on a Japan Spectroscopic Co. Ltd. DIP-1000 in $\mathrm{CHCl}_{3}$. The EIMS were obtained on a JEOL the Tandem MStation JMS700. The IR spectra were determined with a JASCO FT/IR-
470 plus Fourier transform infrared spectrometer. Nuclear magnetic resonance (NMR) spectra were obtained with a JEOL FX-500 (500.00 MHz, $\left.{ }^{1} \mathrm{H} ; 125.65 \mathrm{MHz},{ }^{13} \mathrm{C}\right)$ spectrometer.

Materials Fresh Japanese apricot was obtained from Minabegawa Plum Research Center (Wakayama, Japan).

Media and Bacterial Growth $H$. pylori (H. pylori ATCC43504, American type, culture collected Rokville MD, U.S.A.) was grown on blood agar plates (Trypticase soy agar supplemented with 5\% sheep blood; Becton Dickinson, Tokyo, Japan) for $4 \mathrm{~d}$ at $37^{\circ} \mathrm{C}$ in a microaerophilic atmosphere $\left(10 \% \mathrm{O}_{2}\right.$ and $\left.10 \% \mathrm{CO}_{2}\right)$. The colonies developed were then suspended in brain heart infusion (BHI) broth (Difco) containing 10\% fetal bovine serum (FBS) (Gibco, Gaithersburg, MD, U.S.A.), followed by incubation for 18 to $20 \mathrm{~h}$ at $37^{\circ} \mathrm{C}$ in a microaerophilic atmosphere. The bacterial cultures were subjected to motion analysis.

Motion Analysis Bacterial motility was examined under an inverted, phasecontrast microscope with a Analysis Chamber (Neuroscience Co., Osaka, Japan) of specimens. The motility speed (in micrometers per second) was measured by using a motion analysis system with the program C-Imaging C-MEN (Complix Inc., Cramberry, PA, U.S.A.). Bacterial swimming in a liquid layer of BHI broth containing $10 \%$ FBS between a glass slide and a glass cover (106 to 107 $\mathrm{CFU} / \mathrm{ml}$ ) was continuously recorded 15 times with a $0.05-\mathrm{s}$ analysis time each (a total of $0.75 \mathrm{~s}$ ), and the swimming speed (in micrometers per second) of each bacterial cell in a specimen was obtained. This was performed in at least five different fields of a specimen, the swimming speeds of $c a$. 1000 bacterial cells were collected for each specimen, and the percent of motile bacteria was determined. Brownian motion of bacteria was estimated to be $0.4 \pm 0.3 \mu \mathrm{m} / \mathrm{s}$ using heated or formalin-treated, nonmotile bacteria, and the mean speed of $\geq 4.0 \mu \mathrm{m} / \mathrm{s}$ (speed 10 times higher than that of Brownian motion) was judged as positive motility; bacterial motility was also judged with the naked eye under a phasecontrast microscope. The swimming speed given in the text represents the mean speed of motile bacteria.

Extraction and Isolation The methanol extract of unripe Japanese apricot was fractionated to search for inhibitor 


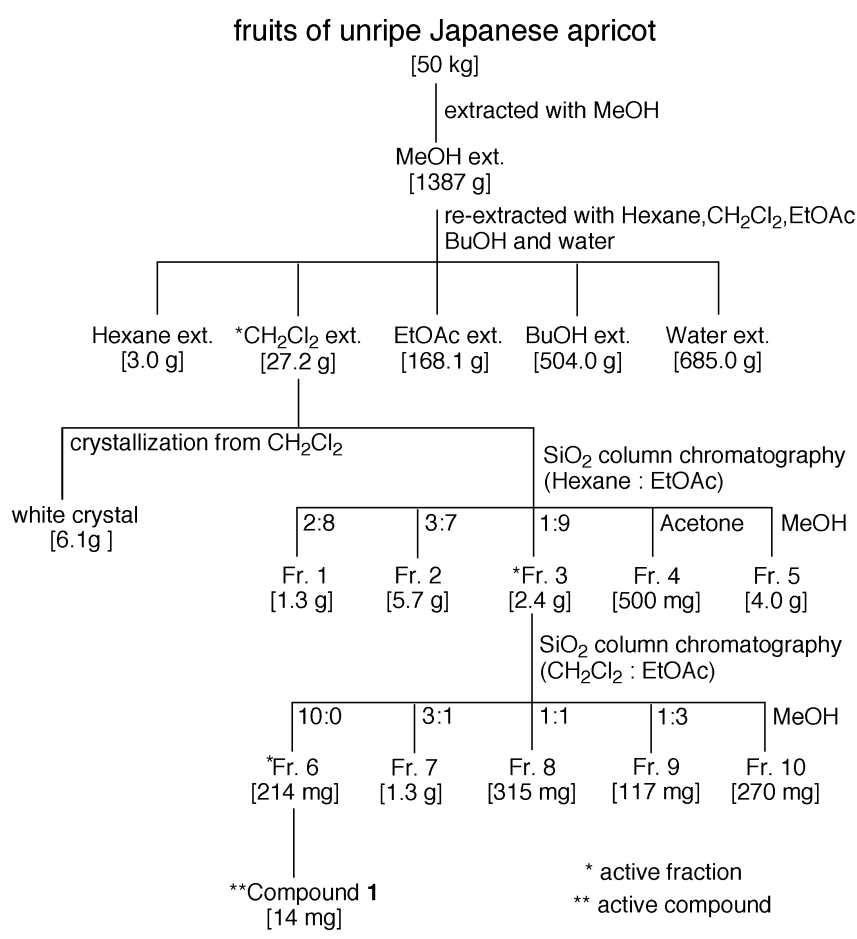

Fig. 1. Isolation Scheme of Inhibitor from Unripe-Japanese Apricot

of $H$. pylori motility (Fig. 1). Unripe Japanese apricot (50 kg) was refluxed with methanol for $12 \mathrm{~h}$ to give a methanol extract $(1387 \mathrm{~g})$. This extract was suspended in water and re-extracted with hexane, dichloromethane, ethyl acetate, butanol and water, respectively. Each fraction was concentrated under reduced pressure to give hexane $(3 \mathrm{~g})$, dichloromethane $(27.2 \mathrm{~g})$, ethyl acetate $(168.1 \mathrm{~g})$, butanol $(504 \mathrm{~g})$, and water $(685 \mathrm{~g})$ fractions. The dichloromethane fraction showed inhibitory effect of $H$. pylori motility. The dichloromethane fraction was fractionated to fractions $1-5$ by silica gel column chromatography with hexane and ethyl acetate as eluents. Fr. 3 showed a potent inhibitory effect. Repeated column chromatography of Fr. 3 on silica gel using motion analysis as a guide afforded inhibitory compound $\mathbf{1}(14 \mathrm{mg})$.

$(+)$-Syringaresinol (1): Needles; mp $184-186^{\circ} \mathrm{C} ;[\alpha]_{\mathrm{D}}^{21}$ $+24.3^{\circ}\left(c=0.1, \mathrm{CHCl}_{3}\right)$; IR $v_{\max }^{\mathrm{KBr}} \mathrm{cm}^{-1}: 3419,1614,1517$, 1461, 1213; EI-MS m/z: $418\left(\mathrm{M}^{+}\right)$.

\section{RESULTS AND DISCUSSIONS}

The methanol extract of unripe Japanese apricot was fractionated to search for suppressive compound of $H$. pylori motility. Test samples were evaluated at concentration of $500 \mu \mathrm{g} / \mathrm{ml}$. The dichloromethane extract exhibited inhibitory effect on the H. pylori motility. To isolate the inhibitor, fractionation of the dichloromethane extract was carried out as described in Fig. 1. The inhibitor was isolated by $\mathrm{SiO}_{2}$ column chromatography and identified as (+)-syringaresinol (Fig. 2) by comparing their spectral data to that previously reported. ${ }^{13,14)}$

Compound 1 was tested for inhibitory effect of $H$. pylori motility. Compound $\mathbf{1}$ inhibited $>90 \%$ of $H$. pylori motility at a concentration of $500 \mu \mathrm{g} / \mathrm{ml}$, and the $\mathrm{IC}_{50}$ value was $50 \mu \mathrm{g} / \mathrm{ml}$. H. pylori has multiple flagella, and exhibits strong motility ${ }^{15)}$ The motility contributed by the flagella is neces-

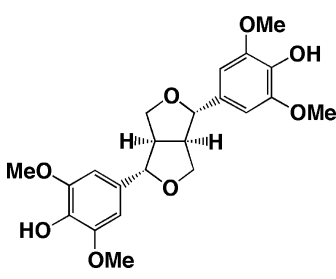

Fig. 2. Chemical Structure of (+)-Syringaresinol

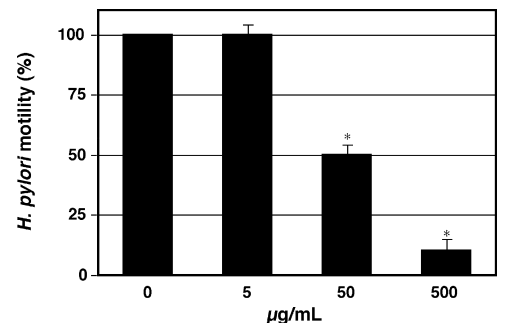

Fig. 3. Inhibitory Effect of Compound $\mathbf{1}$ on the H. pylori Motility

The data represent means \pm standard deviations (error bars) of a thousand H. pylori. $* p<0.05$.

sary for colonization of the gastric moucosa and development of gastritis by $H$. pylori. ${ }^{9,10)}$ Therefore, the inhibition of the motility of the H. pylori is expected to be an efficient approach for prevention of the gastric moucosa by $H$. pylori. Tsutsui et al. reported the inhibitory effects of rabeprazple and its thioether derivative on the motility. ${ }^{16)}(+)-S y-$ ringaresinol (1) showed potent inhibitory effect in vitro $H$. pylori motility assay. Thus, compound $\mathbf{1}$ may prevent the colonization by $H$. pylori of the gastric mucosa and gastritis. To clarify the mechanism of inhibition of $H$. pylori motility by compound $\mathbf{1}$, more studies are necessary.

\section{REFERENCES}

1) Hirayama F. S., Takagi E., Iwao Y., Yokoyama, K., J. Gastroenterol, 34, 450-454 (1999).

2) Sugiyama A., Maruta F., Ikeno T., Ishida K., Kawasaki S., Katsuyama T., Shimizu N., Tatematsu M., Cancer Res., 58, 2067-2069 (1998).

3) Tokieda M., Honda S., Fujioka T., Nasu M., Carcinogenesis, 20, 1261-1266 (1999).

4) Watanabe T., Tada M., Nagai H., Sasaki S., Nakao M., Gastroenterology, 115, 642-648 (1998).

5) Graham D. Y., Gastroenterology, 118, S2-S8 (2000).

6) Megrand F., Aliment Pharmacol. Ther., 11, 43-53 (1997).

7) Wang W. H., Wong B. C. Y., Mukhopadhyay A. K., Berg D. E., Cho C. H., Lai K. C., Hu W. H. C., Fung F. M. Y., Hui W. M., Lam S. K., Aliment Pharmacol. Ther., 14, 901-910 (2000).

8) Kato M., Yamaoka Y., Kim J. J., Reddy R., Asaka M., Kashima K., Osato M. S., El-Zaatari F. A., Graham D. Y., Kwon D. H., Antimicrob. Agents Chemother., 44, 2214-2216 (2000).

9) Eaton K. A., Morgan R. D., Krakowka S., J. Med. Microbiol., 37, 123-127 (1992).

10) Eaton K. A., Suerbaum S., Josenhans C., Krakowka S., Infect. Immun., 64, 2445-2448 (1996)

11) Terada H., Sakabe Y., Eisei Kagaku, 34, 36- 40 (1998).

12) Ohtsubo T., Ikeda F., J. Jpn. Soc. Hortic. Sci., 62, 695-700 (1994)

13) Yuan W. L., Leslie J. H., Andrew D. P., Phytochemistry, 50, 12371241 (1999).

14) Das B., Venkataiah B., Kashinatham A., Fitoterapia, 70, 101-102 (1999).

15) Josenhans C., Labigene A., Suerbaum S., J. Bactriol., 177, 30103020 (1995).

16) Tsutsui N., Taneike I., Ohara T., Goshi S., Kojio S., Iwakura N., Matsumaru H., Akisaka-Saito N., Zhang H.-M., Yamamoto T., Antimicrob. Agents Chemother., 44, 3069-3073 (2000). 